$12 ; 13$

\title{
Экспериментальное исследование влияния внешнего сигнала на режим генерации гиротрона мегаваттного уровня мощности
}

\author{
() В.Л. Бакунин, Ю.А. Гузнов, Г.Г. Денисов, Н.И. Зайцев, \\ С.А. Запевалов, А.Н. Куфтин, Ю.В. Новожилова", А.П. Фокин, \\ А.В. Чирков, А.С. Шевченко
}

Институт прикладной физики РАН, Нижний Новгород, Россия

ฯ E-mail: julia.novozhilova2009@yandex.ru

Поступило в Редакцию 2 ноября 2017 г.

Для гиротрона с мегаваттным уровнем мощности впервые экспериментально исследован захват частоты излучения внешним сигналом. Внешний сигнал от магнетрона на частоте $35 \mathrm{GHz}$ поступал в рабочее пространство гиротрона через синтезированный двухзеркальный квазиоптический преобразователь, позволяющий трансформировать входной сигнал в рабочую моду. Этот преобразователь был недавно разработан и реализован в ИПФ РАН. Экспериментально получены спектры излучения в режимах захвата частоты и биений частоты. Найдена зависимость ширины полосы захвата частоты от мощности внешнего сигнала. Сравнение экспериментальных результатов с данными численного моделирования уравнений гиротрона с внешним сигналом показало их хорошее согласие.

DOI: 10.21883/PJTF.2018.11.46195.17109

Получение одномодовой одночастотной генерации в мощных гиротронах представляет интерес для ряда практических приложений, таких как создание комплекса когерентно излучающих мощных источников микроволнового диапазона - гиротронов. Предшествующие экспериментальные работы по захвату частоты гиротрона сигналом, поступающим из магнетрона, выполнялись для гиротронов с мощностью от десятков до нескольких сотен киловатт и с прямым вводом и выводом излучения через выходной волноводный тракт [1,2]. Такой способ ввода и вывода излучения применим только при невысоком 
уровне мощности излучения (до десятков киловатт). В последние годы появилась возможность реализовать захват частоты гиротрона мегаваттного уровня мощности внешним сигналом при использовании недавно разработанного в ИПФ РАН синтезированного квазиоптического преобразователя [3], позволяющего эффективно трансформировать внешний сигнал в рабочую моду гиротрона. В отличие от традиционных квазиоптических козырьковых преобразователей, трансформирующих входной сигнал в моду со встречным вращением полей, слабо связанную с электронным пучком [4-6], в таком преобразователе направление азимутального вращения полей входной и выходной волн одинаково, и эти волны развязаны в пространстве (рис. 1).

В настоящей работе представлены результаты эксперимента, в котором исследовалось воздействие излучения магнетрона на режим работы гиротрона с уровнем мощности $0.9 \mathrm{MW}$ [7]. Гиротрон представлял собой выходную секцию гироклистрона, работающую в режиме автогенерации рабочей моды $\mathrm{TE}_{7.3}$. СВЧ-излучение магнетрона на частоте $f_{m}$, близкой к частоте автономной генерации выходного резонатора $f_{g}=35.364 \mathrm{GHz}$, подавалось одномодовым волноводом к рупору, формирующему гауссов пучок. Затем это излучение посредством системы зеркал вводилось под заданным углом в синтезированный квазиоптический преобразователь, где оно трансформировалось в рабочую моду $\mathrm{TE}_{7.3}$ (рис. 1). Радиус резонатора гиротрона составлял $R_{r}=22.3 \mathrm{~mm}$, его длина $-50.7 \mathrm{~mm}$, радиус трубчатого электронного пучка был равен $R_{b}=10 \mathrm{~mm}$. Рабочая мода резонатора $\mathrm{TE}_{7.3}$ имела одну продольную вариацию поля в выходном резонаторе. Ведущее магнитное поле было равно $B_{0}=1.5 \pm 0.1 \mathrm{~T}$, ускоряющее напряжение после процесса включения составляло $135 \mathrm{kV}$, ток пучка 46.5 А. При частотах входного сигнала, достаточно близких к частоте автономной генерации гиротрона, наблюдался захват частоты, при более далеких частотах входного сигнала - биения частоты. Спектры излучения и входного сигнала для обоих режимов показаны на рис. 2, a. Была найдена зависимость ширины полосы захвата от уровня мощности входного сигнала магнетрона (рис. 3, тонкая кривая). Мощность входного сигнала магнетрона варьировалась аттенюатором. Уровни входной и выходной мощности измерялись калориметром. Уровень мощности магнетрона без ослабления составлял $25 \mathrm{~kW}$. При максимальной мощности входного сигнала ширина полосы захвата частоты составляла $12 \mathrm{MHz}$. При

Письма в ЖТФ, 2018, том 44, вып. 11 


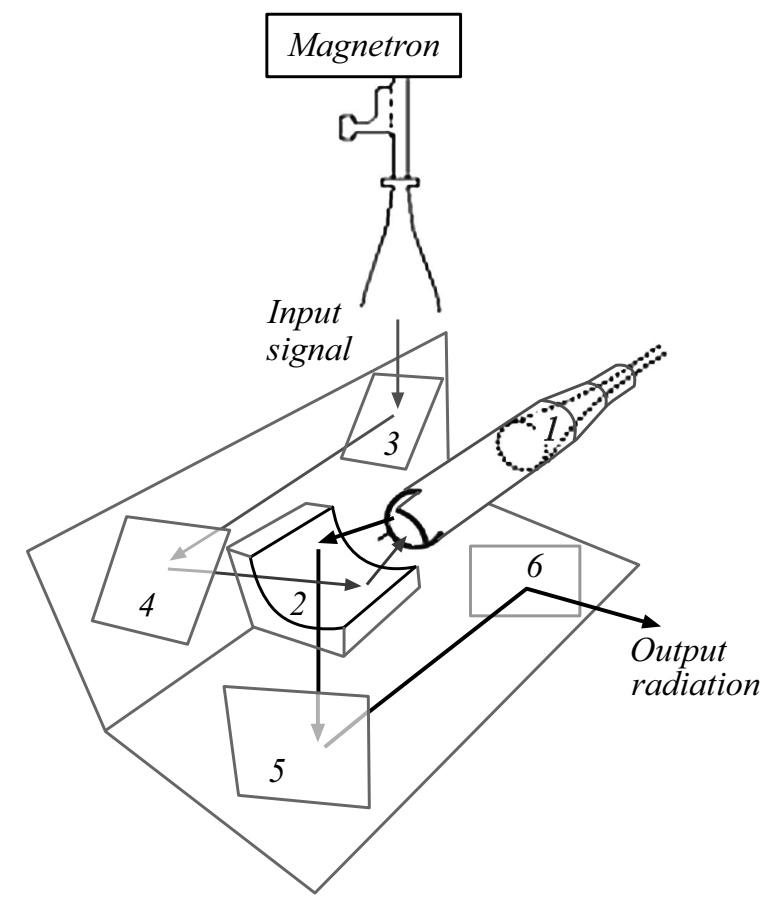

Рис. 1. Схема ввода-вывода излучения в гиротрон. 1 - резонатор гиротрона, 2 - квазипараболическое зеркало, 3,4 - входные зеркала, 5, 6 - выходные зеркала.

уровне сигнала $20 \%$ от максимума (ослабление $7 \mathrm{Db}$ ) эффект захвата частоты пропадал.

Результаты эксперимента были сопоставлены с результатами численного моделирования, проводившегося на основе уравнений возбуждения полей мод и уравнений движения электронов, записанных в приближении фиксированной продольной структуры поля. Эти уравнения приведены в работах $[8,9]$. Приближение фиксированной продольной структуры поля справедливо при достаточно высокой добротности резонатора гиротрона, когда время переходных процессов $Q_{s} / \omega_{s}$ для каждой из взаимодействующих мод много больше времени пролета электронов 


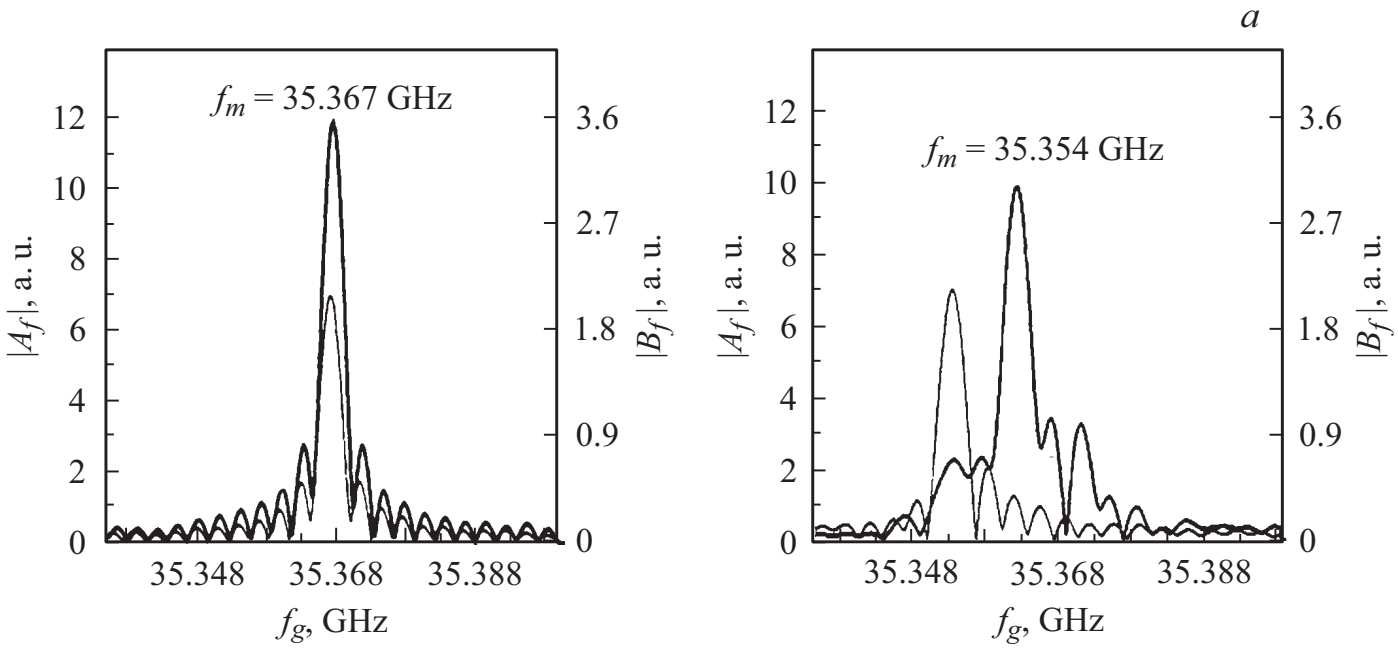

Рис. 2. Результаты эксперимента $(a)$ и расчетов $(b)$ : амплитуды спектров излучения магнетрона $B_{f}$ (тонкие кривые) и гиротрона $A_{f}$ (жирные кривые) в условных единицах измерения для режима захвата (левый столбец) и режима биений (правый столбец). 


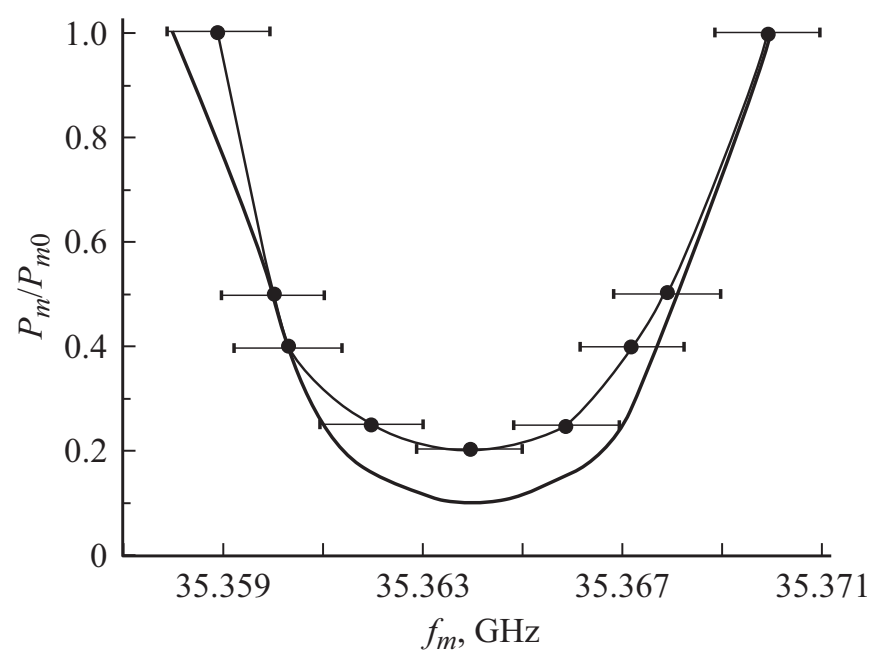

Рис. 3. Экспериментальная (тонкая) и теоретическая (жирная) кривые, ограничивающие снизу область захвата частоты на плоскости двух параметров (мощности и частоты сигнала магнетрона). $P_{m}$ - мощность излучения магнетрона, $P_{m 0}-$ ее максимальное значение. Горизонтальные отрезки соответствуют погрешности измерения частоты.

через резонатор $\left(s-\right.$ номер моды, $Q_{s}$ и $\omega_{s}-$ ее добротность и действительная часть собственной частоты). Указанное условие выполнено, поскольку время переходных процессов при $Q_{s} \approx 1000$ составляет около $5 \mathrm{~ns}$, а время пролета - около $0.3 \mathrm{~ns}$. При моделировании предполагалось, что входные параметры электронного пучка (ток, напряжение) медленно меняются по сравнению с временем пролета электронов через пространство взаимодействия в соответствии со сценарием включения, близким к экспериментальному. Учитывалось взаимодействие пяти мод, лежащих в полосе циклотронного резонанса: рабочей моды $\mathrm{TE}_{7.3}$, ее боковых сателлитов, симметрично отстоящих по частоте $\left(\mathrm{TE}_{6.3}\right.$ и $\left.\mathrm{TE}_{8.3}\right)$, и двух мод встречного вращения $\left(\mathrm{TE}_{-5.4}\right.$ и $\left.\mathrm{TE}_{-4.4}\right)$. Взаимодействие с модами, расположенными вне полосы циклотронного резонанса, несущественно. Частота автономной генерации гиротрона была равна ее экспериментальному значению $35.364 \mathrm{GHz}$. При этом действительная часть холодной частоты резонатора, соответствующей рабочей моде

Письма в ЖТФ, 2018, том 44, вып. 11 
$\mathrm{TE}_{7.3}$, составляла $35.359 \mathrm{GHz}$. Магнитное поле в расчетах принималось равным $1.485 \mathrm{~T}$, что лежит в пределах погрешности экспериментального значения. При таком магнитном поле в процессе включения и выключения напряжения могли возбуждаться паразитные моды $\mathrm{TE}_{6.3}, \mathrm{TE}_{8.3}$ и $\mathrm{TE}_{5.4}$, а после выхода тока и напряжения на постоянные значения происходила генерация только рабочей моды. В эксперименте был неизвестен точно питч-фактор электронного пучка, при расчетах его значение принималось равным 1.2. При моделировании для частоты магнетрона $f_{m}=35.367 \mathrm{GHz}$, близкой к частоте автономной генерации гиротрона, наблюдался захват частоты (рис. 2, $b$, левый столбец), с ростом отстройки частот $\left(f_{m}=35.354 \mathrm{GHz}\right)$ наблюдались биения частоты (рис. 2, $b$, правый столбец). Спектры излучения при захвате частоты и в режиме биений хорошо согласуются с экспериментальными результатами (рис. 2). Результаты расчета границы области захвата частоты на плоскости двух параметров (мощности и частоты сигнала магнетрона), показанные на рис. 3 , также находятся в довольно хорошем согласии с экспериментальными данными. Небольшое расхождение теоретической и экспериментальной кривых на рис. 3 могло быть вызвано погрешностью измерения частоты в эксперименте, которая составляла $\pm 1 \mathrm{MHz}$.

Таким образом, использование синтезированного квазиоптического преобразователя [3] позволило впервые наблюдать захват частоты гиротрона мегаваттного уровня мощности внешним монохроматическим сигналом. Теоретические расчеты хорошо согласуются с результатами эксперимента.

Работа выполнена при поддержке темы госзадания № 0035-2014-0015.

Авторы благодарны А.С. Седову за плодотворные обсуждения.

\section{Список литературы}

[1] Read M.E., Seeley R., Manheimer W.M. // IEEE Trans. Plasma Sci. 1985. V. PS-13. N 6. P. 398-403.

[2] Guo H., Hoppe D.J., Rodgers J., Perez R.M., Tate J.P., Conroy B.L., Granatstein V.L., Bhanii A.M., Latham P.E., Nusinovich G.S. // IEEE Trans. Plasma Sci. 1995. V. 23. N 5. P. 822-832.

Письма в ЖТФ, 2018, том 44, вып. 11 
[3] Chirkov A.V., Denisov G.G., Kuftin A.N. // Appl. Phys. Lett. 2015. V. 106. N 26. P. 263501

[4] Власов С.Н., Орлова И.М. // Изв. вузов. Радиофизика. 1974. Т. 17. № 1. C. $148-154$.

[5] Dumbrajs O. // J. Infrared Millim. Terahertz Waves. 2010. V. 31. N 8. P. 892 898.

[6] Новожслова Ю.В., Рыскин Н.М., Чумакова М.М. // Изв. вузов. Прикладная нелинейная динамика. 2012. Т. 20. № 6. С. 136-147.

[7] Novozhilova Yu.V., Bakunin V.L., Chirkov A.V., Guznov Yu.M., Denisov G.G., Fokin A.P., Shevchenko A.S., Zaitsev N.I., Zapevalov S.A. // EPJ Web Conf. 2017. V. 149. P. 04021.

[8] Бакунин В.Л., Денисов Г.Г., Новожсилова Ю.В., Фокин А.П. // Изв. вузов. Радиофизика. 2016. Т. 59. № 8-9. С. 709-720.

[9] Бакунин В.Л., Денисов Г.Г., Новожсилова Ю.В. // Письма в ЖТФ. 2014. T. 40. B. 9. C. 41-47.

Письма в ЖТФ, 2018, том 44, вып. 11 